\title{
SELECTION OF CHAIN-MATERIAL IN AUTOMOBILE SECTOR USING MULTI ATTRIBUTE DECISION MAKING APPROACH
}

\author{
Harwinder Singh \\ Department of Mechanical Engineering \\ Guru Nanak Dev Engineering College \\ Ludhiana, Punjab-141006, India \\ E-mail: harwin75@rediffmail.com \\ Raman Kumar \\ Department of Mechanical Engineering \\ Chandigarh University, \\ Gharuan, Punjab-140413, India \\ E-mail: ramankakkar@gmail.com
}

\begin{abstract}
The selection of material is a multi-attribute decision problem. In this research work, Analytical Hierarchy Process (AHP) has been implemented to compute subjective weight of criteria and MATLAB programming has been used to computed objective weight of criteria. An attempt has been made to rank out materials on their performance index by using subjective weights as well as objective weights. The use of MATLAB avoids healthy mathematical calculations and it minimizes the possibility of error in statistical calculation. An example has been demonstrated to show the effectiveness of purposed methodology in selection of material. The alternatives have also been ranked and the 2 nd alternate (AISI 1075) has been termed as best chain material.
\end{abstract}

Keywords: material selection, AHP, objective weight, preference index

\section{Introduction}

In this globalization competitive scenario, two wheeler manufacturers are making lot of efforts to manufacture better mileage vehicles at low cost. The Indian two wheeler industry share in automobile industry has increased from $15 \%$ in 2001 to $25 \%$ in 2013. They are facing lot of competition from especially Chinese market. The Chinese market is dominating India market in terms of production volumes and number of manufacturers. To compete in this highly globalized world, India has to take care of designer's parameters such as functional requirements, process ability, cost reliability, resistance to service conditions give emphasis while selection of material in manufacturing industries. The wrong choice of materials may result in loss of productivity and profitability and hence reputation of a manufacturing organization. The rest of the articles are organized as follows: - Section 2 narrates the literature review. Section 3 defines the hypothesis. Section 4 describes the research methodology. Section 5concludes the research and provides suggestions for further research. 


\section{Literature Review}

Literature review reveals that various methodologies have already been used by the past researchers to provide a direction for proper material selection. The performance index of material has been computed by using objective weights. The effort was made for the evaluation of material for bicycle chain. It was suggested to use MATLAB to avoid healthy mathematical calculation [1]. A novel hybrid approach consists of induced ordered weighted averaging standardized distance and VIKOR (IOWA-VIKOR) has been purposed for material selection A case example has been discussed to validate the purposed methodology and compare the result with other methods [2]. An integrated fuzzy based frame model was developed for material handling equipment selection problem. The purposed methodology consists of two different approaches such as Fuzzy Analytic Network Process (FANP) and Fuzzy Preference Ranking Organization Method for Enrichment Evaluations (FPROMETHEE). A real industries problem of a manufacturing company was solved and a sensitivity analysis was so performed to check the sensitivity in ranking of alternates due to changes of the weights [3]. An attempt has been made to bridge the gap in material selection of Pipe material in Sugar Industry. The F-AHP was used to compute weights of attributed and TOPSIS, VIKOR, ELECTRE, PROMETHEE were used to provide ranking of alternates. A comparative analysis was done based on the result obtained from different multi attributes decision making (MADM) approach [4]. A novel MADM approach consists of both objective weights and subjective weight was introduced for material selection for design problem. The fuzzy theory was used to convert qualitative data in to crisp value. Three different examples from literature were discussed with purposed methodology and results were compared with rest of MADM approaches [5].

\section{Hypotheses}

Hypothesis 1- Selection of material for Cycle chain

Hypothesis 2- Develop a program to compute objective weights for criteria

\section{Research Methodology}

\subsection{Implement of AHP}

The AHP methodology as invented by Saaty in 1980 [6].

Step 1:- Data Collection

Five different medium carbon materials such as AISI 1050, AISI 1074, CS 1045, EN 47 and C 50 from material database have been selected for the selection of material for motorcycle chain. The six properties such as Tensile strength (TS) in MPa, Yield strength in MPa (YS), Hardness (BH) in HB, Density (D) in $\mathrm{kg} / \mathrm{m}^{3}$, Elongation in \% (E) and Young's Modulus of elasticity (YM) in GPa has been considered in the present research work. The secondary data of above mentioned parameters was collected from different sources, brainstorming etc. as shown in Table 1.

Table 1. Data of material selection

\begin{tabular}{|c|c|c|c|c|c|c|}
\hline & TS & YS & BH & D & E & YM \\
\hline AISI 1050 & 690 & 580 & 197 & 7850 & 23 & 208 \\
\hline AISI 1074 & 650 & 505 & 192 & 7800 & 10 & 202 \\
\hline CS 1045 & 91 & 77 & 163 & 7870 & 12 & 184 \\
\hline EN 47 & 710 & 415 & 175 & 7700 & 25 & 200 \\
\hline
\end{tabular}


IJAHP Article: Mu, Saaty/A Style Guide for Paper Proposals To Be Submitted to the International Symposium of the Analytic Hierarchy Process 2014, Washington D.C., U.S.A.

\begin{tabular}{|l|l|l|l|l|l|l|} 
C 50 & 610 & 320 & 241 & 7850 & 14 & 205 \\
\hline
\end{tabular}

Step 2:- Draw hierarchy diagram

Three level hierarchy diagram (shown in figure 2) has been used to evaluate the best material. Figure 2 show that level 1 refers to the goal; level 2 composes of the six objectives.

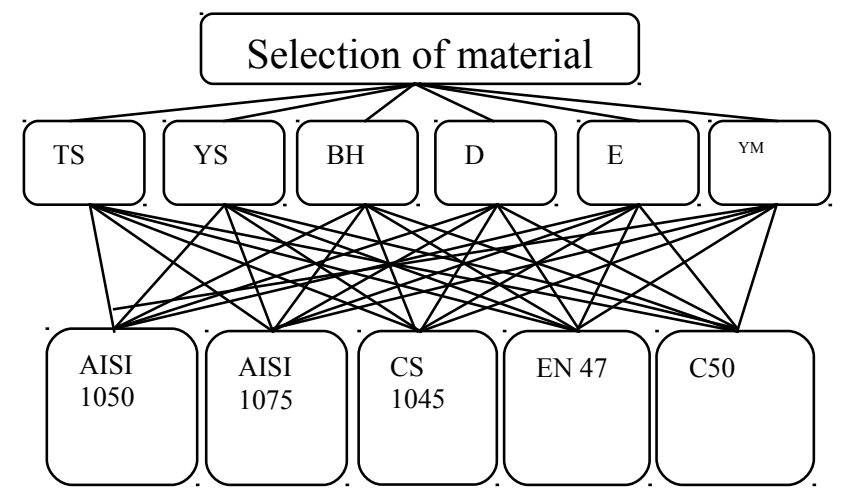

Fig. 1 Hierarchy Diagram

Step 3:- Pair-wise comparison matrix and subjective weight $\left(\mathrm{W}^{\mathrm{S}}\right)$ of criteria The degree of preference or intensity of the decision maker in the choice of each pairwise comparison used in this model is quantified on a scale of 1-9. The Pair-wise comparison matrix and priority weights are shown in Table 2.

Table 2. Pair-wise comparison matrix and priority weight

\begin{tabular}{|c|c|c|c|c|c|c|c|c|}
\hline & TS & YS & $\mathrm{BH}$ & D & E & YM & $\mathrm{W}^{\mathrm{S}}$ & Consistency Test \\
\hline TS & 1 & 1 & 1 & 4 & 3 & 2 & 0.230 & \multirow{3}{*}{$\begin{array}{c}\text { Maximum Eigen } \\
\text { Value }=6.37832\end{array}$} \\
\hline YS & 1 & 1 & 2 & 4 & 4 & 3 & 0.290 & \\
\hline $\mathrm{BH}$ & 1 & $1 / 2$ & 1 & 5 & 5 & 3 & 0.248 & \\
\hline $\mathrm{D}$ & $1 / 4$ & $1 / 4$ & $1 / 5$ & 1 & $1 / 4$ & $1 / 2$ & 0.046 & \multirow{3}{*}{$\begin{array}{l}\text { C.R= C.I/R.I }= \\
0.06102\end{array}$} \\
\hline E & $1 / 3$ & $1 / 4$ & $1 / 5$ & 4 & 1 & 1 & 0.086 & \\
\hline YM & $1 / 2$ & $1 / 3$ & $1 / 3$ & 2 & 1 & 1 & 0.094 & \\
\hline
\end{tabular}

\subsection{Compute the objective weight $\left(\mathrm{W}^{\mathrm{o}}\right)$}

Step 1:- Normalized Matrix

The next step is to divide each entry in column by the sum of entries in column to get value of relative weights.

\section{Step 2:- Calculate the Statistical variance value}

Statistical variance is a measure of the dispersion of a set of data points around their mean value. 
IJAHP Article: Mu, Saaty/A Style Guide for Paper Proposals To Be Submitted to the International Symposium of the Analytic Hierarchy Process 2014, Washington D.C., U.S.A.

Step 3:- Determine objective weights $\left(W^{\circ}\right)$.

The MATLAB program is shown in Appendix A and simulation results of MATLAB are shown in Appendix B. The objective weights are shown in Table 3.

Table 3. Values of objective weights

\begin{tabular}{|c|c|}
\hline Attribute & Objective weights $\left(\mathrm{W}^{\mathrm{O}}\right)$ \\
\hline TS & 0.3928 \\
\hline YS & 0.3919 \\
\hline BH & 0.0350 \\
\hline D & 0.0001 \\
\hline E & 0.2400 \\
\hline YM & 0.0032 \\
\hline
\end{tabular}

Step 4:- Computation of preference index

The preference index $(\mathrm{Pi})$ can be calculated using the following equations and preference index value is shown in Table 4.

$$
\mathrm{PI}^{\mathrm{O}}=\sum_{\mathrm{i}}^{\mathrm{n}} \mathrm{W}^{\mathrm{O}} \mathrm{Xij} ; \quad \mathrm{PI}^{\mathrm{S}}=\sum_{\mathrm{i}}^{\mathrm{n}} \mathrm{W}^{\mathrm{S}} \mathrm{j} \mathrm{Xij} ; \quad \mathrm{PI}^{(\mathrm{O}+\mathrm{S})}=\sum\left(\mathrm{W}^{\mathrm{O}}+\mathrm{W}^{\mathrm{S}}\right) \mathrm{Xij} ;
$$

Table 4. Value of Preference Index value

\begin{tabular}{|c|c|c|c|c|c|c|c|}
\hline \multirow[t]{2}{*}{ Attribute } & \multicolumn{2}{|c|}{$\mathrm{PI}^{\mathrm{O}}$} & \multirow[t]{2}{*}{ Rank } & $\mathrm{PI}^{\mathrm{S}}$ & \multirow[t]{2}{*}{ Rank } & $P \mathrm{I}^{(\mathrm{O}+\mathrm{S})}$ & \multirow[t]{2}{*}{ Rank } \\
\hline & $\mathrm{W}^{\mathrm{o}}=1$ & $\mathrm{~W}^{\mathrm{s}=} 0$ & & $\mathrm{~W}^{\mathrm{o}}=0$ & & \begin{tabular}{|l|l}
$\mathrm{W}^{\mathrm{o}}=0.5$ & $\mathrm{~W}^{\mathrm{s}=} 0.5$
\end{tabular} & \\
\hline $\mathrm{P}_{\text {AISI } 1050}$ & \multicolumn{2}{|c|}{0.858} & 2 & 0.942 & 1 & 0.874 & 2 \\
\hline $\mathrm{P}_{\text {AISI } 1075}$ & \multicolumn{2}{|c|}{0.923} & 1 & 0.931 & 2 & 0.902 & 1 \\
\hline $\mathrm{P}_{\mathrm{CS} 1045}$ & \multicolumn{2}{|c|}{0.322} & 5 & 0.444 & 5 & 0.378 & 5 \\
\hline $\mathrm{P}_{\mathrm{EN} 47}$ & \multicolumn{2}{|c|}{0.744} & 3 & 0.828 & 4 & 0.764 & 3 \\
\hline $\mathrm{P}_{\mathrm{C} 50}$ & \multicolumn{2}{|c|}{0.717} & 4 & 0.839 & 3 & 0.759 & 4 \\
\hline
\end{tabular}

\section{Conclusion}

In present study preference index of different materials have been computed to rank out the alternates. In this work, alternative AISI 1075 is placed at first position on basis of ranking of alternates. The results show that ranking order 2-1-5-3-4 obtained by objective weight and ranking order 1-2-5-4-3 is obtained by subjective weight. The obtained result creates conflict in decision making. Thus preference index has been computed by using combination of subjective and objective weights. The purposed simulated work can be implementing to any decision making problem with minor modification. For future works, it is suggested to compact MATLAB program through advanced tools. The sensitivity analysis can be performed to demonstrate the influence of different criteria weight. Further the study could be extended by using different MADM approaches such as TOPSIS, ELECTRE etc.

\section{References}

[1]. Singh, H. and Kumar, R. (2012). Selection of Material for Bicycle Chain in Indian Scenario using MADM Approach, Proceedings of the World Congress on Engineering 2012, vol III, London, U.K

International Symposium of $\quad 4$ the Analytic Hierarchy

Washington, D. C. Process June 29 - July 2, 2014 
[2.]Liu, H.C., Mao. L.X., Zhang, Z.Y., Li, P. (2013). Induced aggregation operators in the VIKOR method and its application in material selection, Applied Mathematical Modelling, 37 (9), 6325-6338.

[3]Tuzkaya, G., Gulsun, B., Kahraman, C., Ozgen, D. (2010). An integrated fuzzy multi- criteria decision making methodology for material handling equipment selection problem and an application, Expert Systems with Applications, 37 (4), 2853-2863.

[4] Anojkumar, L., Ilangkumaran, M., Sasirekha, V. (2013) Comparative analysis of MCDM methods for pipe material selection in sugar industry, Expert Systems with Applications, 41 (6), 2964-2980.

[5] Rao RV, Patel, BK. (2010). A subjective and objective integrated multiple attribute decision making method for material selection, Materials and Design, 31-10, 2010, 4738-4747.

[6] Saaty, T.L. (1980), The Analytic Hierarchy Process, 3rd ed., McGraw-Hill, New York, NY.

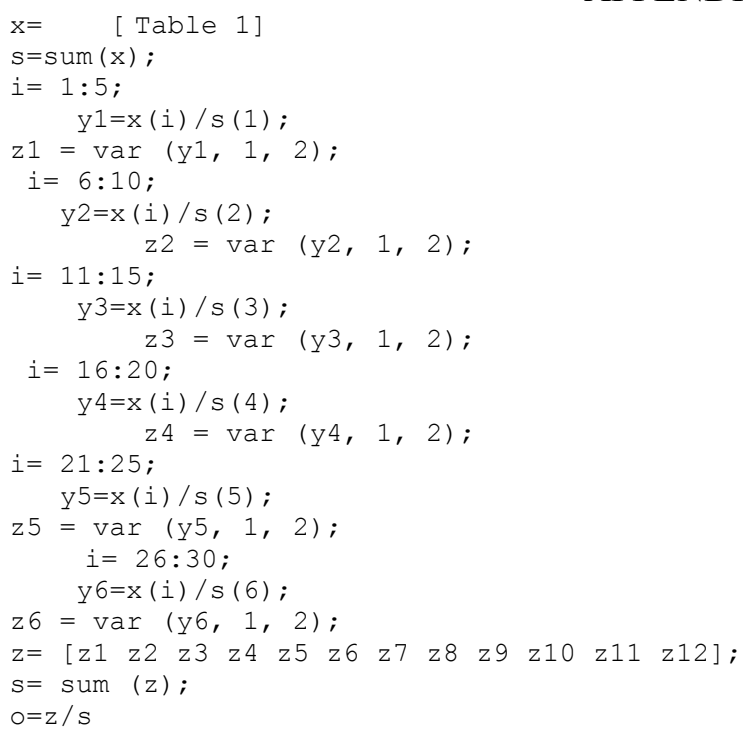

\section{APPENDIX A}

APPENDIX B

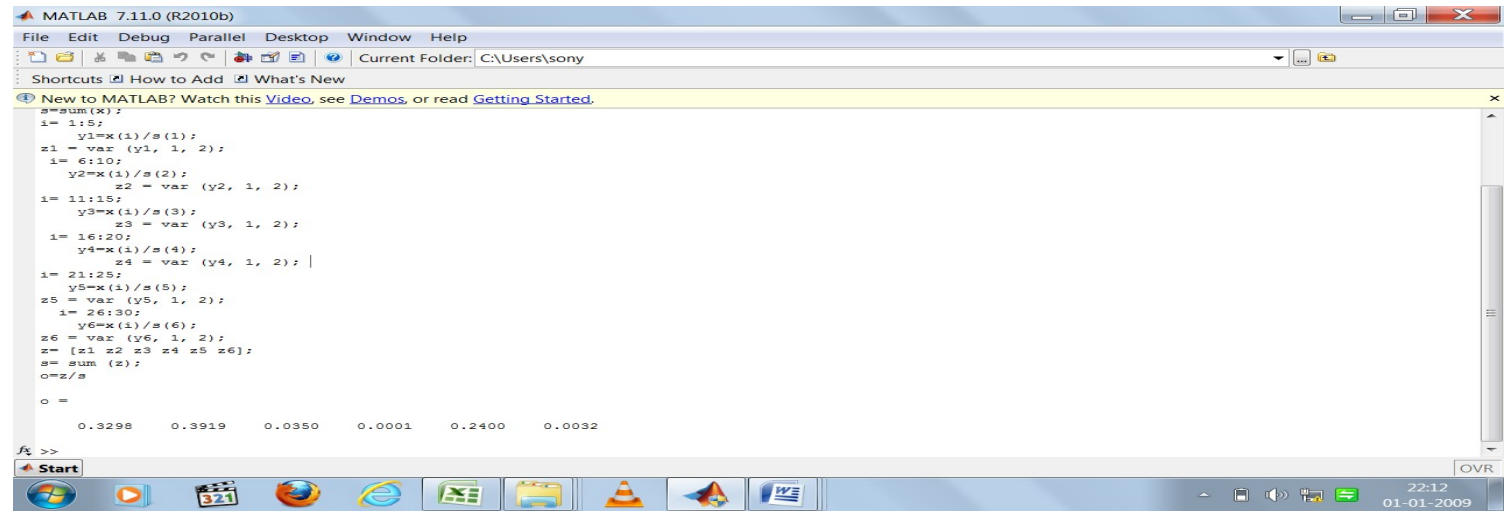

